\title{
Technical efficiency of public district hospitals in Bangladesh: a data envelopment analysis
}

\author{
Sayem Ahmed ${ }^{1,2,3^{*}} \mathbb{D}$, Md. Zahid Hasan' ${ }^{1}$, Samia Laokri' ${ }^{4}$, Zerin Jannat ${ }^{5}$, Mohammad Wahid Ahmed $^{1}$, \\ Farzana Dorin ${ }^{1}$, Veronica Vargas ${ }^{6,8}$ and Jahangir A. M. Khan²,7
}

\begin{abstract}
Background: District hospitals (DHs) provide secondary level of healthcare to a wide range of population in Bangladesh. Efficient utilization of resources in these secondary hospitals is essential for delivering health services at a lower cost. Therefore, we aimed to estimate the technical efficiency of the DHs in Bangladesh.

Methods: We used input-oriented data envelopment analysis method to estimate the variable returns to scale (VRS) and constant returns to scale (CRS) technical efficiency of the DHs using data from Local Health Bulletin, 2015. In this model, we considered workforce as well as number of inpatient beds as input variables and number of inpatient, outpatient, and maternal services provided by the DHs as output variables. A Tobit regression model was applied for assessing the association of institutional and environmental characteristics with the technical efficiency scores.

Results: The average scale, VRS, and CRS technical efficiency of the DHs were estimated to 85\%, 92\%, and 79\% respectively. Population size, poverty headcount, bed occupancy ratio, administrative divisions were significantly associated with the technical efficiency of the DHs. The mean VRS and CRS technical efficiency demonstrated that the $\mathrm{DHs}$, on an average, could reduce their input mix by $8 \%$ and $21 \%$ respectively while maintaining the same level of output.

Conclusion: Since the average technical efficiency of the DHs was 79\%, there is little scope for overall improvements in these facilities by adjusting inputs. Therefore, we recommend to invest further in the DHs for improvement of services. The Ministry of Health and Family Welfare (MoHFW) should improve the efficiency in resource allocation by setting an input-mix formula for DHs considering health and socio-economic indicators (e.g., population density, poverty, bed occupancy ratio). The formula can be designed by learning from the input mix in the more efficient DHs. The MoHFW should conduct this kind of benchmarking study regularly to assess the efficiency level of health facilities which may contribute to reduce the wastage of resources and consequently to provide more affordable and accessible public hospital care.
\end{abstract}

Keywords: Technical efficiency, Secondary hospitals, District hospitals, Data envelopment analysis, Bangladesh

\footnotetext{
*Correspondence: sayemahmed@icddrb.org

${ }^{1}$ Health Systems and Population Studies Division, icddr,b, Dhaka 1212,

Bangladesh

Full list of author information is available at the end of the article
} 


\section{Background}

Sustainable development goals (SDG), developed by the United Nations General Assembly, includes health as a major component to ensure healthy lives and promote well-being for all ages by 2030 [1]. In South Asia, Bangladesh is one of the poorest and densely populated countries. The country had a population of 161 million in 2015. By 2030, this population size is expected to increase to around 218 million [2].

Constitutionally, Bangladesh government is obliged to provide basic healthcare to every citizen. To ensure healthcare for the citizens, the country has built a structured health system covering different healthcare services, health education, health promotion, and rehabilitation. The health systems have a tire structure that includes primary, secondary, and tertiary level of healthcare facilities in communities, sub-districts, districts, and divisions of the country.

The primary level health facilities include Upazila Health Complexes at the sub-districts, Union Health and Family Welfare Centers at the Unions (collection of few villages), and Community Clinics at the villages. District Hospitals or general hospitals (DHs) works as referral centers of these primary level facilities and delivers the secondary level of healthcare including treatment for non-communicable diseases and a number of other specialized cares (e.g. Cardiac, Neuroscience, and Orthopaedic hospitals). The tertiary hospitals (e.g. Medical college hospitals, specialized hospitals) of various kinds provide supports to the primary and secondary level health facilities along with specialized health services [3].

There are 62 DHs across the country and each of the districts has at least one such hospital except Rajshahi and Dhaka. In some districts, the hospitals are called 'general hospital' or '250-bed hospital' [3]. The DHs provide primary and secondary care through the outdoor, indoor (outpatient and inpatient services), and emergency departments [4]. About $6 \%$ of the total outpatient visits and $40 \%$ of the total inpatient admissions in public facilities were served by DHs, and more than $22 \%$ of the total government health expenditure was spent through these facilities in 2015 [3, 5].

Globally, it was estimated that about USD 300 billion were being lost annually due to hospital-related inefficiency [6]. Efficiency studies are important for informed decision making to improve the performance of hospitals and reduce wastage. It is important to reduce the consumption of excessive resources in producing healthcare services for all healthcare system. Efficiency in production invariably results in better allocation of resources and increase the opportunity to serve more beneficiaries. This in turn raises important sustainability and equity implications.
In different countries (e.g. Angola, India, and Ghana) several studies were carried out in assessing the efficiency of healthcare facilities by using data envelopment analysis (DEA) [7-10]. Over the decades, DHs are playing a key role in health systems of Bangladesh as secondary hospitals. However, little has been known about the efficiency of these DHs in this context. In 1999, a study was conducted to assess the efficiency by comparing bed occupancy rate and bed turnover rate of subdistrict level healthcare facilities in Bangladesh using Lasso's graphical model [11]. The finding suggested that large subdistrict hospitals with more beds and staff were efficient and optimal. Vargas et al. 2016 assessed the efficiency of DHs using a similar approach. They found only 12 out of $62 \mathrm{DHs}(19.4 \%)$ with greater inefficiency and around one-third of the hospital with greater efficiency and the remaining hospitals had average efficiency. However, this study only considered two indicators (e.g. bed occupancy rate and bed turnover rate) for efficiency analysis [12] Therefore, efficiency analysis of DHs is required considering multiple input and output variables to compare their level of efficiency. Efficient DHs can contribute considerably toward achieving the health-related targets in SDG. Thus, we aimed to estimate the technical efficiency of the DHs in Bangladesh using DEA.

\section{Methods}

We used secondary data to conduct this cross-sectional study. The efficiency scores of DHs were estimated using an input-oriented DEA [13]. The association of institutional and environmental characteristics with the technical efficiency of the DHs was measured using a Tobit regression model.

\section{Sources of data}

In this study, we used data from the Local Health Bulletin-2015. The bulletin consists of annual hospital service and monitoring statistics which is published annually by the Directorate General of Health Services (DGHS), Ministry of Health and Family Welfare (MoHFW), Bangladesh [3]. Population data was collected from Bangladesh Bureau of Statistics (BBS) and district wise poverty headcounts from The World Bank report [14, 15]. We selected these data sources for extracting input, output and explanatory variables for the efficiency analysis (Table 1).

\section{Selection of input and output variables}

The selection of variables was guided by a literature review on the efficiency analysis and considering the availability of the relevant data [3, 7-10]. Inputs in hospital production are classified as labour, capital and supplies. The labour input can be disaggregated into the various professional groups such as physician, nurse, and 
Table 1 Selected variables and sources of information

\begin{tabular}{|c|c|c|}
\hline Variables & Measuring units (in year 2015) & Source \\
\hline \multicolumn{3}{|l|}{ Input variables } \\
\hline Beds & Total number of beds available & Local health bulletin 2015 [3] \\
\hline Doctors & Total number of doctors (specialists and primary care physicians) available & Local health bulletin 2015 [3] \\
\hline Nurses & Total number of nurses available & Local health bulletin 2015 [3] \\
\hline \multicolumn{3}{|l|}{ Output variables } \\
\hline At least 4 ANC recipients & Total number of women received 4 ANC services & Local health bulletin 2015 [3] \\
\hline Normal deliveries & Total number of normal deliveries & Local health bulletin 2015 [3] \\
\hline Caesarean-section deliveries & Total number of caesarean-section service provided & Local health bulletin 2015 [3] \\
\hline PNC recipients & Total number of women received PNC service & Local health bulletin 2015 [3] \\
\hline Outpatient department visits & Total number of outpatient visits & Local health bulletin 2015 [3] \\
\hline Inpatient admissions & Total number of inpatient admissions & Local health bulletin 2015 [3] \\
\hline \multicolumn{3}{|l|}{ Explanatory variables } \\
\hline Population size & Number of catchment population in the district where the hospital located & Bangladesh Bureau of Statistics [15] \\
\hline Poverty headcount & Proportion of people living below the poverty line in the DHs area & World Bank 2010 [14] \\
\hline Bed occupancy ratio & Proportion of beds occupied over a specific year & Local health bulletin 2015 [3] \\
\hline Average length of stay & Average number of days patients spent in a hospital & Local health bulletin 2015 [3] \\
\hline Ratio of beds to physicians & Total number of beds per physician & Local health bulletin 2015 [3] \\
\hline Ratio of beds to nurses & Total number of beds per nurse & Local health bulletin 2015 [3] \\
\hline
\end{tabular}

administrative staff. Number of hospital beds can be considered as the proxy of capital $[16,17]$. Due to the constraint in data we have used labor (doctors and nurses) and capital (as proxied by number of beds) as the inputs in production of hospital services.

There are two thoughts regarding the measurement of the output of a healthcare organization i.e. process approach (output of a healthcare organisation consists of intermediate services such as number of tests performed or patients served or patient days etc.) and outcome approach (consider health status as ultimate outcome) [18]. In reality, measuring processes or intermediated outcome (services) in healthcare is easier than measuring changes in health status. Further, changes in health outcome cannot be entirely attributed to healthcare as health is multi-dimensional and affected significantly by a host of other socioeconomic factors. Thus, we selected at least 4th antenatal care (ANC) recipients, normal deliveries, caesarean (C)-section deliveries, post-natal care (PNC) recipients, outpatient department (OPD) visits, and inpatient admissions as output variables in DEA.

\section{Explanatory variables}

The explanatory variables for a Tobit regression were selected based on review of literature on efficiency analysis $[16,19,20]$. Factors that affect the efficiency of DHs were classified to environmental factors i.e. catchment population, administrative locations, and poverty headcount and institutional factors i.e. average length of stay (ALoS), bed occupancy ratio (BOR), ratio of beds to physicians (RoBTP), and ratio of beds to nurse (RoBTN) (Table 1).

\section{The data envelopment analysis}

DEA is widely used for estimating the technical efficiency of a set of decision making units (DMUs) that accommodates multiple inputs and outputs [21]. DEA approach assumes that a set of DMUs is associated with their corresponding amount of inputs and outputs. The efficiency score is defined as a ratio of the weighted sum of the outputs to the weighted sum of the inputs [22]. It is based on a non-parametric linear programming technique which identifies an efficiency frontier on which only the efficient DMUs are placed. A DMU is considered to be technically efficient if it can produce maximum output from a given set of inputs.

In estimating the efficiency frontier, Charnes, Cooper, and Rhodes (CCR) assumed production as constant returns to scale (CRS) which means any level of increase in inputs will proportionately increase the level of output [13]. Another model proposed by Banker, Charnes, and Cooper (BCC), assumed that production as variable returns to scale (VRS) that means any increase in the level of input will either increase or decrease the level of output [23]. In the VRS assumption, a DMU may result in increasing returns to scale (IRS) or decreasing returns to scale (DRS). When output increases by a greater proportion than the increase in inputs, the production process is called IRS. On the 
other hand, when output increases by a smaller proportion than the increase in inputs, the production process is called DRS.

The health services production process is not linear and the VRS technical efficiency assumption in health service production may be more appropriate [10]. However, we demonstrated two types of technical efficiency, namely, CRS technical efficiency; estimated based on the CCR model and VRS technical efficiency; estimated based on the BCC model to allow the comparison of findings between two methods $[13,23]$. The scale efficiency is a measure of the extent to which a DMU deviates from an optimal scale. When a DMU is operating at CRS, technical efficiency is equal to scale efficiency as CRS technical efficiency denotes that technical efficiency of a DMU cannot be attributed to deviations from optimal scale (required optimal size for given input and output mix). The scale efficiency is represented by the ratio of the scores from CRS technical efficiency and VRS technical efficiency [24].

We have utilized an input-oriented DEA model as it focuses on minimizing the use of inputs for producing the given amount of outputs. This model fits with the context of DHs since these hospitals can control over the inputs such as staffing and operating expenses or beds, rather than on how many patients get admitted or visits [25]. Our operating units or DMUs are 62 DHs for which three inputs and six outputs variables (Table 1) were selected for analysis.

\section{Input oriented model}

The input-oriented VRS DEA model is specified as follows,

$$
\begin{gathered}
\mathrm{Eff}=\operatorname{Max} \sum a_{r} y_{r j_{0}}+a_{0} \\
\mathrm{a}_{\mathrm{r}}, \mathrm{b}_{\mathrm{i}}
\end{gathered}
$$

Subject to

$$
\begin{aligned}
& \sum a_{r} y_{r j}-\sum b_{i} x_{i j}+a_{0} \leq 0 ; \forall \mathrm{j} \\
& \sum b_{i} x_{i j_{0}}=1 \\
& \mathrm{a}_{\mathrm{r},} \mathrm{b}_{\mathrm{i}} \geq 0 ; \forall \mathrm{r}, \forall \mathrm{i}
\end{aligned}
$$

where $y_{r j}$ is the amount of output $r$ produced by DH j; $x_{i j}$ is the amount of input $i$ used by DH j; $a_{r}$ is the weight for output $r$; $b_{i}$ is the weight for input $i$; is the total number of $\mathrm{DH}$, and $\mathrm{j}_{0}$ is the considered $\mathrm{DH} ; \forall=$ for all.

The efficiency score of the DHs ranges between 0 and 1. DHs that are technically efficient have a score of one or $100 \%$, whereas, the inefficient DHs have efficiency scores of less than 1 or less than $100 \%$.

\section{Tobit regression analysis}

To measure the association between the inefficiency scores and number of explanatory variables we used a Tobit regression model. Since, by definition, the DEA scores range between zero and one, and some of the data tend to concentrate on these boundary values (i.e., censored for the DMUs with a value at one), ordinary least squares can not estimate the regression. For the convenience of the calculation, we assumed a censoring point at zero in this model. As a result, the efficient DHs will have score zero and the inefficient DHs will have score greater than zero. Following [26], this was performed by transforming CRS and VRS technical efficiency scores into CRS and VRS inefficiency scores and left censoring at zero as follows.

Inefficiency score $=(1 /$ Technical efficiency score $)-1$.

Both CRS and VRS technical inefficiency scores were regressed separately to estimate the association between technical efficiency scores and selected institutional and environmental characteristics (Table 1). The Tobit regression models were specified as follows,

Ineff $_{i}=\beta_{0}+\beta_{1}$ POP $_{i}+\beta_{2}$ Poverty $_{i}+\beta_{3}$ Division $_{i}+\beta_{4}$ ALoS $_{i}$

$$
+\beta_{5} \text { BOR }_{i}+\beta_{6} \text { RoBTP }_{i}+\beta_{7} \operatorname{RoBTN}_{i}+\varepsilon_{i}
$$

where Ineff is the technical inefficiency score; POP is the categorical varible of regional population $(1=$ if population is less than 1,000,000; $2=$ if population is above $1,000,000$ to $2,500,000$ and $3=$ above $2,500,000$ ); Division is a categorical variable for eight different divisions (1=Barisal, $2=$ Chittagong, $3=$ Dhaka, $4=$ Khulna, $5=$ Mymensingh, $6=$ Rajshahi $7=$ Rangpur and $8=$ Syl het). The ALoS, BOR, RoBTP, and RoBTN were included as continuous variable in the models. Finally, $\varepsilon i$ was the stochastic error term.

\section{Results}

Descriptive statistics of the selected input and output variables of the DHs are shown in Table 2. The number of beds varied from 100 to 278 with a mean and standard deviation (SD) of 148 and 70 respectively. The average number of doctors (specialists and primary care physicians) and nurses was 23 and 60 respectively in the DHs. The average number of OPD visits was 149,625 patients and inpatient admission was 24,915 patients.

Table 3 presents the estimated CRS and VRS technical efficiency, scale efficiency, and returns to scale score of each DHs. The mean CRS technical efficiency was 79\%, VRS technical efficiency was $92 \%$, and scale efficiency was $85 \%$. In total, 18 (29\%) were CRS technically efficient among the 62 DHs. Among the remaining 44 inefficient DHs, the mean CRS technically efficiency was $70 \%$. The 
Table 2 Descriptive statistics of input and output variables

\begin{tabular}{|c|c|c|c|c|c|}
\hline Variables & Mean & $\begin{array}{l}\text { Standard deviation } \\
\text { (SD) }\end{array}$ & Median & Minimum & Maximum \\
\hline \multicolumn{6}{|l|}{ Inputs } \\
\hline Number of beds & 148 & 70 & 100 & 100 & 278 \\
\hline $\begin{array}{l}\text { Doctors (specialists and primary care physi- } \\
\text { cians) }\end{array}$ & 23 & 13 & 19 & 5 & 60 \\
\hline Nurses & 60 & 34 & 49 & 12 & 159 \\
\hline \multicolumn{6}{|l|}{ Outputs } \\
\hline Number of 4 ANC recipients & 1679 & 2811 & 888 & - & 18,548 \\
\hline Number of normal deliveries & 1093 & 824 & 857 & - & 5368 \\
\hline Number of C-section deliveries & 624 & 546 & 463 & - & 2756 \\
\hline Number of women received PNC & 2607 & 2595 & 1832 & 66 & 17,493 \\
\hline Number of OPD visits & 149,625 & 59,594 & 136,596 & 42,383 & 312,797 \\
\hline Number of admissions & 24,915 & 15,612 & 20,964 & 2235 & 85,005 \\
\hline
\end{tabular}

Gopalganj 250 Bedded District Hospital had the lowest such efficiency (48\%).

In terms of VRS technical efficiency, total 49 DHs (79\%) were found to be efficient. The 13 inefficient DHs were on an average $63 \%$ efficient. The efficiency level of Bandarban district hospital was the lowest (36\%) in VRS. Total $18(29 \%)$ DHs were found to be scale-efficient in VRS model. Among the 44 scale-inefficient DHs, 31 (70.5\%) had IRS, and 13 (29.6\%) had DRS.

The majority of the DHs had all three types of efficiency scores (CRS technical efficiency, VRS technical efficiency, and scale efficiency) between 0.80 and 1.00 (Fig. 1). A few number of the DHs had VRS technical efficiency and scale efficiency less than 0.60 .

Table 4 shows the mean efficiency scores of DHs by administrative divisions in Bangladesh. In Sylhet division, both CRS technical efficiency (0.71) and VRS technical efficiency (0.79) scores were the lowest among the administrative divisions. However, CRS technical efficiency score was the highest in Rangpur division, and VRS technical efficiency was the highest in Khulna division. The average scale efficiency score was the highest in Rajshahi division (0.94) and the lowest in Barisal division (0.78).

The results of the Tobit regression model utilizing the CRS technical efficiency and VRS technical efficiency scores are presented in Table 5. The DHs with target population over 2.5 million had higher CRS technical efficiency compared to DHs with target population less than 1 million. The DHs located in a district with poverty headcount $15 \%$ to $30 \%$ had higher CRS technical efficiency and VRS technical efficiency than the DHs located in a district with poverty headcount less than $15 \%$. Among the administrative division in Bangladesh, DHs in Chittagong, Dhaka, Khulna, Mymensingh had higher
CRS efficiency than the DHs in Barisal. However, DHs in Sylhet division were less VRS technical efficient than the DHs in Barishal division. The coefficient was positive and statistically significant. As expected the CRS technical efficiency score of DHs increased with the increment of bed occupancy ratio and ratio to bed to physicians and nurses.

\section{Discussion}

The findings reflected that on an average the DHs were technically efficient. The average CRS technically efficiency was $79 \%$ and VRS technically efficiency was $92 \%$, and therefore, using resources optimally. The level of technical efficiency is high because of the high utilization of DHs in Bangladesh. Another study using simple indicators of hospital performance and Pabon Lasso model, observed similar findings on the efficiency of DHs in Bangladesh [12]. The mean VRS and CRS technical efficiency score of the DHs may reflect that these DHs, on an average, could reduce their input mix by $8 \%$ and $21 \%$ respectively while maintaining the same level of output. However, most of these hospitals are functioning beyond their capacities since the average bed-occupancy rate of DHs was 137\% (CI 121-147) in 2015 [3]. Therefore, there is a little scope for increase in efficiency gains in these hospitals by reducing inputs, and instead, additional investment on more beds and other accompanying resources will be required in order to improve outcomes. A study on the comparative efficiency of the healthcare facilities of Bangladesh showed that the DHs were more cost-efficient compared to the primary level Upazila health complexes [11].

Studies on the efficiency of the DHs conducted using DEA approach reported different findings in different settings. A study conducted in China 
Table 3 Technical and scale efficiency scores and returns to scale characteristics of district hospital

\begin{tabular}{|c|c|c|c|c|}
\hline Hospitals & $\begin{array}{l}\text { CRS technical efficiency } \\
\text { score }\end{array}$ & $\begin{array}{l}\text { VRS technical efficiency } \\
\text { score }\end{array}$ & $\begin{array}{l}\text { Scale efficiency } \\
\text { score }\end{array}$ & $\begin{array}{l}\text { Returns } \\
\text { to scale }\end{array}$ \\
\hline Bagerhat District Hospital (BhD) & 0.90 & 1.00 & 0.90 & 1 \\
\hline Bandarban District Hospital (BbD) & 0.36 & 1.00 & 0.36 & 1 \\
\hline Barguna District Hospital (BuD) & 0.93 & 1.00 & 0.93 & 1 \\
\hline Barisal General Hospital (BrG) & 0.50 & 1.00 & 0.50 & 1 \\
\hline Bhola District Hospital (BID) & 1.00 & 1.00 & 1.00 & 0 \\
\hline Bogra 250 bed Mohammad Ali District Hospital (BgD) & 0.47 & 0.49 & 0.96 & 1 \\
\hline Brahmanbaria 250 bed District Sadar Hospital (BmD) & 1.00 & 1.00 & 1.00 & 0 \\
\hline Chandpur 250 bed General Hospital (CnD) & 0.49 & 0.53 & 0.94 & -1 \\
\hline ChapaiNawabganj District Hospital (CpD) & 0.97 & 1.00 & 0.97 & 1 \\
\hline Chittagong General Hospital (CtD) & 0.51 & 0.54 & 0.94 & -1 \\
\hline Chuadanga District Hospital (CdD) & 0.99 & 1.00 & 0.99 & 1 \\
\hline Comilla General Hospital (CID) & 0.59 & 1.00 & 0.59 & 1 \\
\hline Coxs Bazar 250 Bed District Sadar Hospital (CbD) & 1.00 & 1.00 & 1.00 & 0 \\
\hline Dinajpur General Hospital (DnD) & 0.52 & 0.53 & 0.98 & -1 \\
\hline Faridpur General Hospital (FdD) & 1.00 & 1.00 & 1.00 & 0 \\
\hline Feni 250 bed District Sadar Hospital (FdS) & 0.69 & 0.87 & 0.79 & -1 \\
\hline Gaibandha District Hospital (GdD) & 0.84 & 1.00 & 0.84 & 1 \\
\hline Gazipur District Hospital (GiD) & 0.62 & 1.00 & 0.62 & 1 \\
\hline Gopalganj 250 Bedded District Sadar Hospital (GpD) & 0.46 & 0.48 & 0.97 & -1 \\
\hline Habiganj District Hospital (HgD) & 1.00 & 1.00 & 1.00 & 0 \\
\hline Jamalpur 250 bed General Hospital (JmD) & 0.63 & 0.72 & 0.87 & -1 \\
\hline Jessore 250 bed General Hospital (JeG) & 0.79 & 1.00 & 0.79 & -1 \\
\hline Jhenaidah District Hospital (JdD) & 1.00 & 1.00 & 1.00 & 0 \\
\hline Jholakathi District Hospital (JID) & 0.68 & 1.00 & 0.68 & 1 \\
\hline Joypurhat District Hospital (JpD) & 0.74 & 0.80 & 0.93 & -1 \\
\hline Khagrachari District Hospital (KcD) & 0.83 & 1.00 & 0.83 & 1 \\
\hline Khulna General Hospital (kuD) & 0.50 & 0.67 & 0.74 & 1 \\
\hline Kishoreganj 250 bed District Sadar Hospital (KgD) & 0.90 & 1.00 & 0.90 & -1 \\
\hline Kurigram District Hospital (KiD) & 0.89 & 1.00 & 0.89 & 1 \\
\hline Kushtia 250 bed General Hospital (KsD) & 0.79 & 1.00 & 0.79 & -1 \\
\hline Lakshmipur District Hospital (LhD) & 0.93 & 1.00 & 0.93 & 1 \\
\hline Lalmonirhat District Hospital (LmD) & 0.72 & 1.00 & 0.72 & 1 \\
\hline Madaripur District Hospital (MdD) & 0.61 & 1.00 & 0.61 & 1 \\
\hline Magura District Hospital (MuD) & 0.93 & 1.00 & 0.93 & 1 \\
\hline Manikganj District Hospital (MnD) & 0.84 & 1.00 & 0.84 & 1 \\
\hline Meherpur District Hospital (MrD) & 1.00 & 1.00 & 1.00 & 0 \\
\hline Moulvibazar 250 bed District Sadar Hospital (MbD) & 0.54 & 0.60 & 0.90 & -1 \\
\hline Munshiganj District Hospital (MgD) & 0.74 & 1.00 & 0.74 & 1 \\
\hline Naogaon District Hospital (NgD) & 0.89 & 1.00 & 0.89 & 1 \\
\hline Narail District Hospital (NaD) & 0.69 & 1.00 & 0.69 & 1 \\
\hline Narayanganj General Hospital (NyD) & 1.00 & 1.00 & 1.00 & 0 \\
\hline Narsingdi District Hospital (NsD) & 0.72 & 1.00 & 0.72 & 1 \\
\hline Narsingdi District Hospital (Development) (NrD) & 1.00 & 1.00 & 1.00 & 0 \\
\hline Natore District Hospital (NtD) & 1.00 & 1.00 & 1.00 & 1 \\
\hline Netrokona District Hospital (NkD) & 1.00 & 1.00 & 1.00 & 0 \\
\hline Nilphamari District Hospital (NpD) & 1.00 & 1.00 & 1.00 & 0 \\
\hline Noakhali 250 bed General Hospital (NhD) & 0.65 & 0.67 & 0.96 & -1 \\
\hline Pabna 250 bed General Hospital (PnG) & 1.00 & 1.00 & 1.00 & 0 \\
\hline Panchagarh 100 bed District Sadar Hospital (PcD) & 1.00 & 1.00 & 1.00 & 0 \\
\hline
\end{tabular}


Table 3 (continued)

\begin{tabular}{|c|c|c|c|c|}
\hline Hospitals & $\begin{array}{l}\text { CRS technical efficiency } \\
\text { score }\end{array}$ & $\begin{array}{l}\text { VRS technical efficiency } \\
\text { score }\end{array}$ & $\begin{array}{l}\text { Scale efficiency } \\
\text { score }\end{array}$ & $\begin{array}{l}\text { Returns } \\
\text { to scale }\end{array}$ \\
\hline Patuakhali 250 bed Sadar Hospital (PtS) & 0.60 & 0.77 & 0.78 & 1 \\
\hline Pirojpur District Hospital (PrD) & 0.48 & 1.00 & 0.48 & 1 \\
\hline Rajbari District Hospital (RjD) & 0.78 & 1.00 & 0.78 & 1 \\
\hline Rangamati General Hospital (RgD) & 0.39 & 1.00 & 0.39 & 1 \\
\hline Saidpur 50 Beded Hospital (SiD) & 1.00 & 1.00 & 1.00 & 0 \\
\hline Satkhira District Hospital (StD) & 1.00 & 1.00 & 1.00 & 0 \\
\hline Serajganj General Hospital (SgD) & 0.85 & 1.00 & 0.85 & -1 \\
\hline Shahid Shamsuddin Hospital—Sylhet (SID) & 0.77 & 1.00 & 0.77 & 1 \\
\hline Shariatpur District Hospital (SpD) & 1.00 & 1.00 & 1.00 & 0 \\
\hline Sherpur 100 bed District Sadar Hospital (SrD) & 0.76 & 1.00 & 0.76 & 1 \\
\hline Sunamganj 250 bed District Sadar Hospital (SnD) & 0.52 & 0.56 & 0.93 & 1 \\
\hline Tangail 250 bed District Hospital (TnD) & 1.00 & 1.00 & 1.00 & 0 \\
\hline Thakurgaon District Hospital (TgD) & 1.00 & 1.00 & 1.00 & 0 \\
\hline Mean & 0.79 & 0.92 & 0.85 & - \\
\hline Median & 0.83 & 1.00 & 0.92 & - \\
\hline Standard deviation & 0.20 & 0.16 & 0.16 & - \\
\hline Minimum & 0.36 & 0.48 & 0.36 & - \\
\hline Maximum & 1.00 & 1.00 & 1.00 & - \\
\hline
\end{tabular}

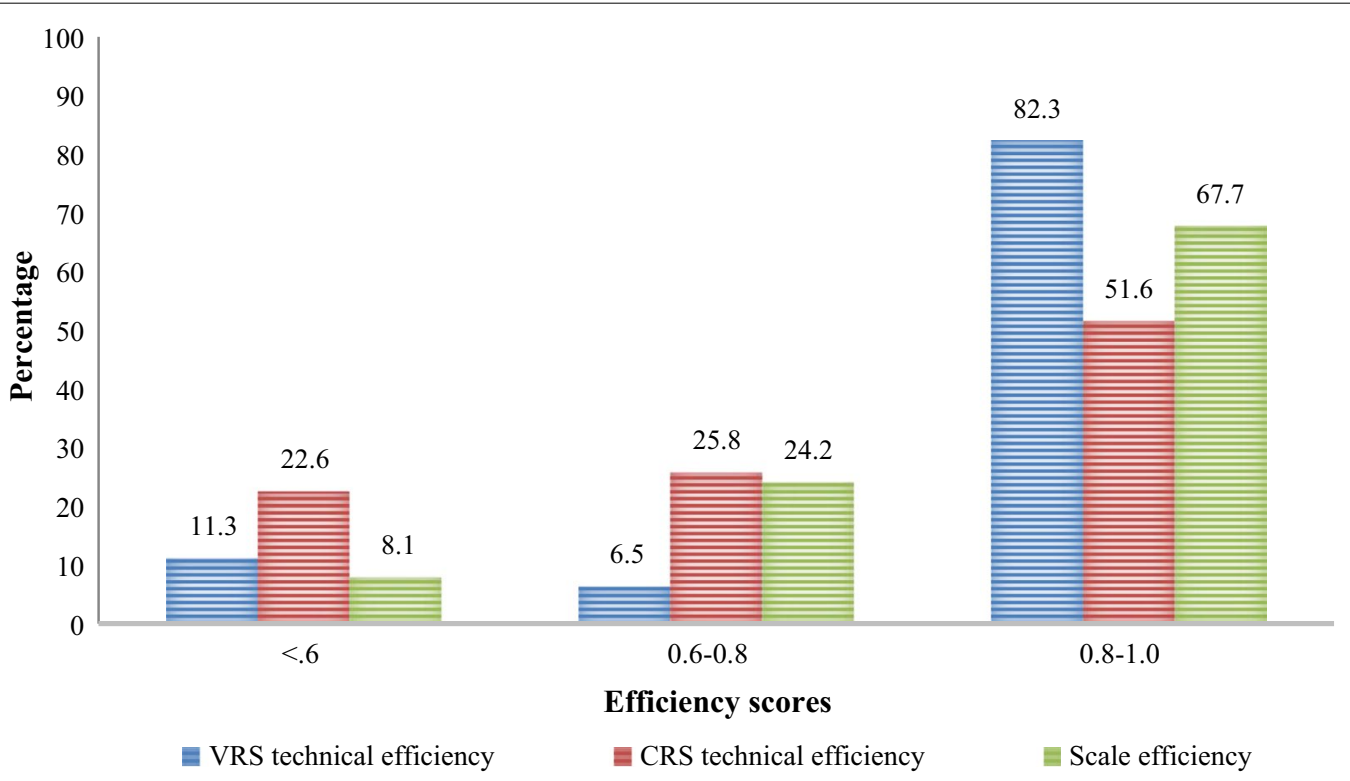

Fig. 1 Percentage distribution of the district hospitals by technical (VRS and CRS) and scale efficiency scores

found that only $8.8 \%$ of DHs were technically efficient in CRS technical efficiency and $15.8 \%$ DHs were technically efficient in VRS technical efficiency [20]. Another study conducted in Ghana found that out of 128 DHs, 31 (24\%) were VRS technically efficient [27]. Two separate studies conducted in India reported that among the DHs studied, 50\% were technically efficient in VRS technical efficiency $[9,28]$. Thus, the available evidence indicated that technical efficiency scores vary among the DHs in Bangladesh, India, Ghana, Namibia, and China. This variation can be due to the associated environmental factors that influence the inputs and outputs of DHs of the countries.

The mean VRS technical efficiency scores were 0.92 and the CRS technical efficiency scores were 0.79 for DHs in Bangladesh. The findings of mean VRS technical efficiency score were similar to studies conducted in 
Table 4 Mean technical and scale efficiency scores of the district hospitals by division

\begin{tabular}{lllll}
\hline Name of the divisions & $\begin{array}{l}\text { Number of hospitals } \\
(\mathbf{N = 6 2 )}\end{array}$ & $\begin{array}{l}\text { Mean } \\
\text { CRS technical efficiency score }\end{array}$ & $\begin{array}{l}\text { Mean } \\
\text { VRS technical efficiency score }\end{array}$ & $\begin{array}{l}\text { Mean } \\
\text { Scale efficiency score }\end{array}$ \\
\hline Barisal & 6 & 0.75 & 0.96 & 0.78 \\
Chittagong & 11 & 0.67 & 0.87 & 0.79 \\
Dhaka & 13 & 0.82 & 0.96 & 0.86 \\
Khulna & 10 & 0.83 & 0.97 & 0.85 \\
Mymensingh & 3 & 0.79 & 0.91 & 0.87 \\
Rajshahi & 7 & 0.85 & 0.90 & 0.94 \\
Rangpur & 8 & 0.87 & 0.94 & 0.93 \\
Sylhet & 4 & 0.71 & 0.79 & 0.90 \\
\hline
\end{tabular}

Table 5 Determinants of inefficiencies in district hospitals of Bangladesh

\begin{tabular}{|c|c|c|}
\hline Variables & $\begin{array}{l}\text { Coefficient (dependent variable }=\text { CRS } \\
\text { technical inefficiency) }\end{array}$ & $\begin{array}{l}\text { Coefficient (dependent variable }=\text { VRS } \\
\text { technical inefficiency) }\end{array}$ \\
\hline \multicolumn{3}{|l|}{ Population } \\
\hline 1 to 2.5 million (Ref $\leq 1$ million) & $-0.117(-0.345,0.111)$ & $0.091(-0.122,0.304)$ \\
\hline Over 2.5 million (Ref $\leq 1$ million) & $-0.238^{*}(-0.497,0.021)$ & $0.059(-0.183,0.301)$ \\
\hline \multicolumn{3}{|l|}{ Poverty headcount } \\
\hline $15 \%$ to $30 \%(\operatorname{Ref} \leq 15 \%)$ & $-0.422^{* *}(-0.784,-0.059)$ & $-0.376^{* *}(-0.720,-0.032)$ \\
\hline $30 \%>(\operatorname{Ref} \leq 15 \%)$ & $-0.256(-0.601,0.090)$ & $-0.340^{* *}(-0.669,-0.011)$ \\
\hline Bed occupancy ratio & $-0.637^{* * *}(-0.813,-0.462)$ & $-0.248^{* * *}(-0.407,-0.090)$ \\
\hline Average length of stay & $0.031(-0.016,0.078)$ & $0.026(-0.018,0.070)$ \\
\hline Ratio of beds to physicians & $-0.046^{* * *}(-0.074,-0.018)$ & $-0.006(-0.031,0.020)$ \\
\hline Ratio of beds to nurses & $-0.055^{* *}(-0.109,-0.000)$ & $0.009(-0.043,0.060)$ \\
\hline \multicolumn{3}{|l|}{ Administrative division } \\
\hline Chittagong (Ref= Barisal) & $-0.372^{* *}(-0.718,-0.027)$ & $0.007(-0.288,0.303)$ \\
\hline Dhaka $($ Ref $=$ Barisal) & $-0.442^{* * *}(-0.761,-0.124)$ & $-0.060(-0.335,0.214)$ \\
\hline Khulna (Ref = Barisal) & $-0.291^{*}(-0.619,0.038)$ & $0.059(-0.226,0.345)$ \\
\hline Mymensingh (Ref= Barisal) & $-0.242(-0.664,0.180)$ & $0.136(-0.243,0.515)$ \\
\hline Rajshahi (Ref= Barisal) & $-0.461^{* *}(-0.818,-0.105)$ & $0.133(-0.182,0.448)$ \\
\hline Rangpur (Ref=Barisal) & $-0.248(-0.550,0.054)$ & $0.086(-0.186,0.358)$ \\
\hline Sylhet (Ref= Barisal) & $0.022(-0.355,0.399)$ & $0.337^{*}(-0.010,0.684)$ \\
\hline Constant & $2.363^{* * *}(1.602,3.124)$ & $0.616^{*}(-0.063,1.294)$ \\
\hline Sigma & $0.256^{* * *}(0.205,0.307)$ & $0.244^{* * *}(0.198,0.289)$ \\
\hline $\mathrm{N}$ & 62 & 62 \\
\hline Log-likelihood & -10.74 & -3.845 \\
\hline Chi square (10) & 56.71 & 23.32 \\
\hline$p$-value & 0.000 & 0.08 \\
\hline R-square & 0.730 & 0.752 \\
\hline
\end{tabular}

${ }^{*} \mathrm{p}<0.10,{ }^{* *} \mathrm{p}<0.05,{ }^{* * *} \mathrm{p}<0.01$

India (0.90) and Ghana $(0.89)[9,10]$. A study in Namibia revealed that mean CRS technical efficiency was less than $75 \%$ [29].

Our study revealed that only $29 \%$ of the DHs were scale efficient meaning they operate at the required optimal size. The prevalent scale inefficiency was the highest (50\%) in IRS. In the presence of IRS, expansion of output reduces unit cost. The hospital management does not require to increase the output level if there is no demand for that increased output [29]. However, increasing output level is not feasible in Bangladesh context since the over-capacity utilization already observed for DHs [3]. Therefore, the hospitals can be expanded to make them scale-efficient.

We extended the DEA analysis by using a Tobit model to identify influential factors that may lead to 
the existing inefficiency of the DHs. It was found that population size (over 2.5 million), poverty headcount, BOR, ALoS, RoBTP, and RoBTN had a significant influence on inefficiency regarding CRS technical efficiency scores. While population size, poverty headcount, BOR, and division had a significant influence on inefficiency regarding VRS technical efficiency. The result showed that using CRS technical efficiency, the DHs with large catchment population (over 2.5 million) had a lower chance of inefficiency than the DHs with the small catchment population ( $<1$ million). The possible reason could be the allocation of resources/inputs in DHs may not be according to catchment populations in Bangladesh. Therefore, there are possibilities of wastage in the hospitals with small catchment population since the DGHS is currently using bed size of the DHs as the main resource allocation criteria. The efficiency in resource allocation should be improved and contexualized by setting an input-mix formula for DHs considering health and socio-economic indicators (e.g., population density, poverty, bed occupancy ratio). The formula can be designed by learning from the input mix in the efficient DHs. The poverty headcount was negatively associated with inefficiency ( $\mathrm{p}$-value $<0.05$ ) of the DHs which implied that such hospitals covering high poverty area were comparatively more efficient than the hospitals covering low poverty area. The findings could be attributable to the fact that public facilities (e.g., DHs) are more utilized by the poor people than the rich people in Bangladesh [30,31]. The BOR was negative and significantly associated with technical inefficiency, indicating that technically inefficient DHs had a lower BOR. The RoBTN and RoBTP were negative and significantly associated with technical inefficiency which implied that the lower number of beds for each nurse or lower RoBTN were technically inefficient. However, the average RoBTN of the DHs was 2.94 which was higher than the developed countries (approximately 0.33) [32]. The DHs may operate using minimum human resource cost (i.e., higher RoBTP and higher RoBTN) to get higher efficiency, as it was found by the Tobit model. However, such minimum human resource allocation may affect the service quality of the DHs and consequently, this will affect the relationship between doctors and patients [20].

This study has several limitations. Firstly, the DEA approach, in general, cannot apprehend quality of health services. Secondly, we could not adjust the hospitals in terms of input-output mix therefore this may affect the interpretation for input variables reductions and expansions of the DHs. However, we studied DHs with similar case-mix that can address the issue for all DHs. Thirdly, due to the unavailability of information, several other input indicators such as the price of the drugs and the cost of the treatment were not included in this study. Since drugs, medical supplies, and equipment are procured centrally by the Central Medical Store Depot (CMSD) of the MoHFW, the prices may not vary widely across the DHs [33]. Therefore, drug price may not affect the estimated efficiency scores of the DHs. However, despite these limitations, this is the first study which estimates the technical and scale efficiency of the DHs of Bangladesh using multiple inputs and outputs variables.

\section{Conclusion}

Health managers or policymakers need information about how well the DHs are utilizing the available resources to improve the performance of DHs in Bangladesh. Using routinely available data, this study shed light on the efficiency of the DHs applying DEA to understand the comparable score across the facilities. The findings of this efficiency study provided empirical evidence on the efficiency level of public DHs in Bangladesh and associated institutional and environmental factors. The average efficiency score of the inefficient DHs was 63\% (13 of 62 in VRS technical efficiency) and 70\% (44 of 62 in CRS technical efficiency). These DHs would need to improve their performance. The higher technical efficiency of the DHs is likely to facilitate better utilization of resources, control the cost of medical services, and consequently to provide more affordable healthcare. The policymakers and hospital managers can use the efficiency estimate of this study to promote benchmarking among the DHs where inefficient DHs can learn from efficient DHs. The MoHFW can set input mix for DHs considering different important resource allocation factors (e.g., population density, poverty) to avoid inefficiency. The DHs at having a maximum and minimum level of efficiency should be investigated further to understand how and why the services provision systems are operating differently at these DHs. Further studies can be conducted to explore the causes of inefficiency in DHs. The policymakers can develop context-based strategies for the inefficient DHs to improve their efficiency in delivering healthcare which may be useful to address the unmet need for healthcare services in Bangladesh.

\footnotetext{
Abbreviations

ALOS: Average length of stay; ANC: Antenatal care; BBS: Bangladesh Bureau of Statistics; BCC: Banker, Charnes, and Cooper; BOR: Bed occupancy ratio; CCR: Charnes, Cooper, and Rhodes; CMSD: Central Medical Store Depot; CRS: Constant returns to scale; DEA: Data envelopment analysis; DGHS: Directorate General of Health Services; DHs: District hospitals; DMUs: Decision making units; DRS: Decreasing returns to scale; IRS: Increasing returns to scale; MoHFW: Ministry of Health and Family Welfare; OPD: Outpatient department; PNC: Post-natal care; RoBTN: Ratio of beds to nurse; RoBTP: Ratio of beds to
} 
physicians; SD: Standard deviation; SDG: Sustainable development goals; USD: United States Dollar; VRS: Variable returns to scale.

\section{Acknowledgements}

icddr,b is grateful to the Governments of Bangladesh, Canada, Sweden, and the UK for providing core/unrestricted support. The authors would like to thank to the MIS department of the DGHS, MoHFW of Bangladesh for providing access to the Local Health Bulletin-2015 database.

\section{Authors' contributions}

$\mathrm{SA}, \mathrm{MZH}$, and JAMK were involved in study design, literature search, data analysis, interpretation, writing, revising, and finalizing the manuscript. SL, $\mathrm{ZJ}, \mathrm{MWA}, \mathrm{FD}$, and WV contributed to interpretation, writing, and revising the manuscript. All authors finally reviewed the manuscript critically. All authors read and approved the final manuscript.

\section{Funding}

The authors did not receive any funding for conducting this study.

\section{Availability of data and materials}

The datasets used during the current study are available at MIS Local Health Bulletin of DGHS. http://app.dghs.gov.bd/localhealthBulletin2015/publish/.

\section{Ethics approval and consent to participate}

This article does not contain any studies with human participants or animals performed by any of the authors.

\section{Competing interests}

The authors declare that they have no competing interests.

\begin{abstract}
Author details
${ }^{1}$ Health Systems and Population Studies Division, icddr,b, Dhaka 1212, Bangladesh. ${ }^{2}$ Department of Learning, Informatics, Management and Ethics (LIME), Karolinska Institutet, SE-171 77 Stockholm, Sweden. ${ }^{3}$ Department of Tropical Biology, Liverpool School of Tropical Medicine, Liverpool L3 5QA, UK. ${ }^{4}$ Global Community Health and Behavioral Sciences, School of Public Health and Tropical Medicine, Tulane University, New Orleans, LA 70112, USA. ${ }^{5}$ Department of Economics, Stockholm University, SE-106 91 Stockholm, Sweden. ${ }^{6}$ Alberto Hurtado University, Santiago, Chile. ${ }^{7}$ Department of International Public Health, Liverpool School of Tropical Medicine, Liverpool L3 5QA UK. ${ }^{8}$ The Lakshmi Mittal And Family South Asia Institute, Harvard University, Cambridge, MA 02138, USA.
\end{abstract}

Received: 26 January 2018 Accepted: 10 July 2019

Published online: 24 July 2019

\section{References}

1. United Nations. N1529189. Gen Assem 70 Sess. 2015. https://doi. org/10.1007/s13398-014-0173-7.2.

2. The World Bank. World Bank population data. Washington DC: The World Bank; 2017.

3. DGHS. Health bulletin 2015. Dhaka: Directorate General of Health Services; 2016

4. Ahmed SM, Alam BB, Anwar I, Begum T, Huque R, Khan JAM, Nababan H, Osman FA. Bangladesh health system review. Geneva: World Health Organization; 2015.

5. MoHFW. Bangladesh national health accounts 1997-2012. Dhaka: Ministry of Health and Family Welfare; 2015. https://doi.org/10.13140/ rg.2.1.3951.6247

6. WHO. The world health report: health systems financing: the path to universal coverage. Geneva: World Health Organisation; 2010.

7. Masiye F. Investigating health system performance: an application of data envelopment analysis to Zambian hospitals. BMC Health Serv Res. 2007;7:58.

8. Kirigia JM, Emrouznejad A, Gama Vaz R, Bastiene H, Padayachy J. A comparative assessment of performance and productivity of health centres in Seychelles. Int J Product Perform Manag. 2007;57:72-92.

9. Jat TR, Sebastian MS. Technical efficiency of public district hospitals in Madhya Pradesh, India: a data envelopment analysis. Glob Health Action. 2013;6:21742
10. Osei D, d'Almeida S, George MO, Kirigia JM, Mensah AO, Kainyu LH. Technical efficiency of public district hospitals and health centres in Ghana: a pilot study. Cost Eff Resour Alloc. 2005;3:9.

11. Rannan-eliya RP, Somanathan A. Bangladesh health facility efficiency study report. Colombo: Institute of Policy Studies;1998.

12. Vargas $V$, Begum T, Ahmed S, Smith O. Fiscal space for health in Bangladesh. Dhaka: The World Bank;2016. https://doi.org/10.13140/rg.2.1.1153.3040.

13. Charnes A, Cooper WW, Rhodes E. Measuring the efficiency of decision making units. Eur J Oper Res. 1978:2:429-44.

14. The World Bank. Zila level poverty map estimates, 2010. Dhaka: The World Bank; 2010

15. BBS. Population and housing census 2011. Dhaka: Bangladesh Bureau of Statistics; 2011.

16. Worthington AC. Frontier efficiency measurement in health care: a review of empirical techniques and selected applications. Med Care Res Rev. 2004;61:135-70.

17. Novignon J, Nonvignon J. Improving primary health care facility performance in Ghana: efficiency analysis and fiscal space implications. BMC Health Serv Res. 2017;17:1-8.

18. Mersha T. Output and performance measurement in outpatient care. Omega. 1989;17:159-67.

19. Kirigia JM, Emrouznejad A, Sambo LG. Measurement of technical efficiency of public hospitals in Kenya: using data envelopment analysis. J Med Syst. 2002:26:39-45.

20. Cheng Z, Tao H, Cai M, Lin H, Lin X, Shu Q, Zhang R. Technical efficiency and productivity of Chinese county hospitals: an exploratory study in Henan province, China. BMJ Open. 2015:5:e007267.

21. Ozcan YA. Performance measurement using data envelopment analysis (DEA). Health care benchmarking and performance evaluation. New York: Springer; 2008. p. 15-41.

22. Mardani A, Zavadskas EK, Streimikiene D, Jusoh A, Khoshnoudi M. A comprehensive review of data envelopment analysis (DEA) approach in energy efficiency. Renew Sustain Energy Rev. 2017;70:1298-322.

23. Banker RD, Charnes A, Cooper WW. Some models for estimating technical and scale inefficiencies in data envelopment analysis. Manag Sci. 1984;30:1078-92.

24. Chattopadhyay S, Ray SC. Technical, scale, and size efficiency in nursing home care: a nonparametric analysis of Connecticut homes. Health Econ. 1996;5:363-73.

25. Nayar P, Ozcan YA, Yu F, Nguyen AT. Benchmarking urban acute care hospitals. Health Care Manag Rev. 2013;38:137-45.

26. Zere E. Hospital efficiency in sub-Saharan Africa evidence. Helsinki: United Nations University; 2000.

27. Jehu-Appiah C, Sekidde S, Adjuik M, Akazili J, Almeida SD, Nyonator F, Baltussen R, Asbu EZ, Kirigia JM. Ownership and technical efficiency of hospitals: evidence from Ghana using data envelopment analysis. Cost Eff Resour Alloc. 2014;12:9.

28. Bhat R, Verma BB, Reuben E. Hospital efficiency: an empirical analysis of district hospitals and grant-in-aid hospitals in Gujarat. J Health Manag. 2001;3:167-97.

29. Zere E, Mbeeli T, Shangula K, Mandlhate C, Mutirua K, Tjivambi B, Kapenambili W. Technical efficiency of district hospitals: evidence from Namibia using data envelopment analysis. Cost Eff Resour Alloc. 2006:4:5.

30. BDHS. Bangladesh demographic and health survey 2014. Dhaka: National Institute of Population Research and Training(NIPORT); 2014.

31. Khan JAM, Ahmed S, MacLennan M, Sarker AR, Sultana M, Rahman H. Benefit incidence analysis of healthcare in Bangladesh — equity matters for universal health coverage. Health Policy Plan. 2017;32:359-65.

32. WHO. World health statistics. Geneva: World Health Organization; 2010.

33. MoHFW. Health bulletin 2014. Dhaka: Directorate General of Health Services; 2015.

\section{Publisher's Note}

Springer Nature remains neutral with regard to jurisdictional claims in published maps and institutional affiliations. 